\title{
Prevention of retinal capillary basement membrane thickening in diabetic dogs by a non-steroidal anti-inflammatory drug
}

\author{
T. A. Gardiner ${ }^{1}$, H. R. Anderson ${ }^{1}$, T. Degenhardt ${ }^{2}$, S. R. Thorpe ${ }^{2}$, J. W. Baynes ${ }^{2,3}$, D. B. Archer ${ }^{1}$, A. W. Stitt ${ }^{1}$ \\ ${ }^{1}$ Department of Ophthalmology, Institute of Clinical Science, Queen's University of Belfast, Royal Victoria Hospital, Belfast, \\ Northern Ireland, UK \\ ${ }^{2}$ Department of Chemistry and Biochemistry, University of South Carolina, Columbia, South Carolina, USA \\ ${ }^{3}$ School of Medicine, University of South Carolina, Columbia, South Carolina, USA
}

\section{Abstract}

Aims/hypothesis. To investigate the effect of treatment with the non-steroidal anti-inflammatory drug Sulindac on the early vascular pathology of diabetic retinopathy in the dog, and it's effect on recognised biochemical indices of hyperglycaemia-related pathophysiology.

Methods. Experimental diabetes (streptozotocin/alloxan) was induced in 22 male beagle dogs and 12 of the animals were assigned at random to receive oral Sulindac $(10 \mathrm{mg} / \mathrm{kg}$ daily). Age- and sex-matched control animals were maintained as non-diabetic controls. After 4 years, several morphological parameters were quantified in the retinal microvasculature of each animal group using an established stereological method. Also, the following diabetes-associated biochemical parameters were analysed: accumulation of advanced glycation end products (AGEs), red blood cell polyol levels and antioxidant status.

Results. Diabetes increased red blood cell sorbitol levels when compared to non-diabetic controls $(p \leq 0.05)$, however, there was no difference in sorbitol levels between the untreated and the treated diabetic animals. No significant differences were found in red blood cell myoinositol levels between the three groups of animals. Pentosidine and other AGEs were increased two- to three-fold in the diabetic animals $(p \leq 0.001)$ although treatment with Sulindac did not affect their accumulation in diabetic skin collagen or alter diabetesinduced rises in plasma malondialdehyde. Retinal capillary basement membrane volume was significantly increased in the untreated diabetic dogs compared to non-diabetic controls or Sulindac-treated diabetic animals $(p \leq 0.0001)$.

Conclusion/interpretation. This study has confirmed the beneficial effect of a non-steroidal anti-inflammatory drug on the early vascular pathology of diabetic retinopathy. However the treatment benefit was not dependent on inhibition of polyol pathway activity, advanced glycation, or oxidative stress. [Diabetologia (2003) 46:1269-1275]

Keywords Sulindac, stereology, diabetic retinopathy.
Received: 25 November 2002 / Revised: 7 March 2003

Published online: 12 July 2003

(C) Springer-Verlag 2003

Corresponding author: Prof. A. W. Stitt, Department of Ophthalmology, Institute of Clinical Science, Queen's University of Belfast, Royal Victoria Hospital, Belfast, BT12 6BA Northern Ireland, UK

E-mail: a.stitt@qub.ac.uk

Abbreviations: AGEs, Advanced glycation end-products; BM, basement membrane; CEL, N-(carboxyethyl)lysine; CML, N(carboxymethyl)lysine; EM, electron microscopy; FL, fructoselysine; MDA, malondialdehyde; NSAID, non-steroidal anti-inflammatory drug; TBARS, thiobarbituric acid-reactive substances.
Non-proliferative diabetic retinopathy is typified by formation of a complex array of vasodegenerative lesions within the microvascular bed of the retina. Retinopathy represents a major complication of diabetes and progression to the proliferative form of the disease or development of macular oedema remains a leading cause of visual impairment. It is now well established that hyperglycaemia constitutes a major risk factor for retinopathy in both Type 1 and Type 2 diabetes [1]. Nevertheless the relative contribution of the various biochemical sequelae of hyperglycaemia remains ill-defined [2]. It is clear however that the pathogenesis of this diabetic complication is highly 
complex and it remains important to develop therapeutic approaches to prevent or retard the vaso-degeneration that predisposes to the sight-threatening stages of diabetic retinopathy [2].

A common early lesion of diabetic retinopathy in human patients and a diverse range of animal models is capillary basement membrane (BM) thickening. It is uncertain if this pathology is of primary or secondary importance in the development of diabetic microangiopathy but BM-modifications could contribute to impaired endothelial-pericyte communication, capillary contractility or appropriate cell interaction with constituent BM proteins $[3,4]$. Thickening of retinal capillary BMs occurs within 6 months of induction of diabetes and this hallmark pathology of diabetic microvascular disease has been extensively studied in the retina $[5,6]$ and used in the evaluation of drug-mediated modulation of diabetic retinopathy in a range of animal models $[7,8,9]$.

The non-steroidal anti-inflammatory drug (NSAID) Sulindac is an effective inhibitor of cyclo-oxygenase and is used clinically in the treatment of arthritis [10] and cancer [11]. Sulindac inhibits aldose reductase in lens [12] and has in vitro activity similar to that of sorbinil [13]. Within the context of diabetes, Sulindac prevents accumulation of sorbitol in cataract and neurones incubated in high glucose [12]. NSAIDs have been shown to be effective against defined lesions of diabetic retinopathy in rats [14] and dogs [15]. With particular relevance to the current investigation, one previous study showed that Sulindac prevented thickening of retinal capillary basement membrane in diabetic cats [9].

In order to study the effect of a well-characterised NSAID on the development of diabetes-induced retinopathic lesions in a long-term model that reproduces most of the pre-proliferative lesions of diabetic retinopathy, we have examined the effects of Sulindac on retinopathy in the diabetic dog. Retinal data has been obtained through a comprehensive analysis of markers relating to dysregulation of key chemical, biochemical and metabolic pathways to provide useful insights into the mechanisms underlying retinal microvasculopathy in diabetes.

\section{Materials and Methods}

We used 30 healthy laboratory-bred male adult beagles weighing 11 to $17 \mathrm{~kg}$ with no history of eye disease or diabetes and these were randomly rendered diabetic $(n=22)$ or retained as normal non-diabetic controls $(n=8)$. Experimental diabetes was induced by a single cocktail injection of a streptozotocin $(35 \mathrm{mg} / \mathrm{kg})$ and alloxan $(40 \mathrm{mg} / \mathrm{kg})$ as previously described [16]. Throughout the experiment, blood glucose concentrations were measured twice daily in all diabetic animals before feeding and maintained between 15 and $23 \mathrm{mmol} / \mathrm{l}$ by a single daily injection of Insulatard isophane insulin. Immediately following establishment of diabetes, half of the diabetic group was assigned at random to receive a daily oral dose of Sulindac $(10 \mathrm{mg} / \mathrm{kg})$ administered before feeding. The dosage of this drug was based on previous studies using Sulindac on diabetic animals [9]. The dogs in this study were coded so that each assay could be analysed "blind".

All animals were housed in individual kennels and fed on a diet of tripe and biscuit fortified with vitamins and minerals and were weighed weekly throughout the 4-year duration of the experiment. Experiments were conducted in compliance with UK Home Office regulations.

Stereology and transmission electron microscopy. After 4 years all animals were killed and the eyes removed. The anterior segment and vitreous were dissected from one eye of each animal and the resulting eye cup immediately fixed for transmission electron microscopy by immersion in $2.5 \%$ glutaraldehyde in $0.1 \mathrm{M}$ sodium cacodylate buffer.

The stereological method used to estimate volume and surface area of the retinal capillaries has been described previously [17. Briefly, five to six cylindrical vertical cores were cut from the central retina using $3 \mathrm{~mm}$ trephine blades. The sites of sampling were selected to include all quadrants of the central retina but never closer than a disc-diameter to the optic disc. The samples had a random orientation to all other retinal features. This sampling method ensured that the samples of retina for stereological analysis were uniformly random, that is, every part of the central retina had an equal chance of being sampled. The trephines of retina were then washed in $0.1 \mathrm{~mol} / \mathrm{l}$ sodium cacodylate buffer, post-fixed in osmium tetroxide, dehydrated and embedded in Spurr's resin in a flat electron microscopy (EM) mould. One semi-thin $1 \mu \mathrm{m}$ and one serial array of ultrathin EM sections were cut from each of four trephines taken from the right eye of each animal. The semi-thin sections were stained with toluidine blue and the EM sections with uranyl acetate and lead citrate. The use of circular trephine blades as samples ensured that the sections of retina which were cut fulfilled the criteria essential for the accurate generation of vertical sections [18]. Vertical sections must be taken at $90^{\circ}$ to an arbitrary fixed plane in the specimen and they must be free to rotate about the vertical axis while still maintaining the $90^{\circ}$ angle to the horizontal.

Through the use of modern stereological models and geometric probes it is possible to generate 3-dimensional quantitative data from 2-dimensonal, transverse sections of retina and a previously published, detailed protocol was followed in the current investigation [17]. The stereological analysis quantified surface area and the volume of retinal capillary BM. This approach had the major advantage that all retinal capillaries in a tissue sample could be used for analysis as compared to nonstereological quantitation where only perfectly transverse sections of retinal capillaries are usable.

Biochemical analysis of blood. Every 12 months following diabetes-induction, throughout the period of the experiment and immediately prior to death, blood samples were collected from each animal after an overnight fast and before Sulindac administration. Levels of total glycated haemoglobin were measured using an affinity chromatography assay which included any glycated haemoglobin variants. The reference range of this assay for canine glycated haemoglobin in non-diabetic animals was 1.7 to $4.9 \%$.

Plasma levels of malondialdehyde (MDA) were also measured as a marker of lipid peroxidation and hence enhanced oxidative stress by high performance liquid chromatography (HPLC) [19]. This form of the thiobarbituric acid for assay of MDA minimises non specific interferences which can occur in assays of total thiobarbituric acid reactive substances 
Table 1. Glycaemia, red blood cell polyol levels, body weights and kidney weights

\begin{tabular}{lccc}
\hline & Controls & Untreated diabetics & Sulindac-treated diabetics \\
\hline Animals/group & 8 & 10 & 12 \\
Mean Daily Blood Glucose $(\mathrm{mmol} / \mathrm{l})$ & $4.4 \pm 1.1$ & $16.9 \pm 3.34$ & $16.0 \pm 3.9$ \\
Glycated haemoglobin at 4 years $(\%)$ & $3.03 \pm 0.8$ & $6.9 \pm 1.6$ & $7.30 \pm 1.1$ \\
Kidney weight $(\mathrm{g})$ & $45.6 \pm 9.2$ & $68.1 \pm 13.0$ & $71.2 \pm 7.6$ \\
RBC sorbitol at 4 years $\left(\mu \mathrm{g} \cdot \mathrm{ml}^{-1}\right)$ & $0.93 \pm 0.56$ & $2.09 \pm 1.53$ & $2.61 \pm 1.5$ \\
RBC myoinositol $\left(\mu \mathrm{g} \cdot \mathrm{ml}^{-1}\right)$ & $3.29 \pm 0.41$ & $4.34 \pm 1.01$ & $5.54 \pm 1.59$ \\
RBC Glucose $\left(\mu \mathrm{g} \cdot \mathrm{ml}^{-1}\right)$ & $104.4 \pm 15.9$ & $516.9 \pm 112.5$ & $461.7 \pm 121.8$ \\
RBC Fructose $\left(\mu \mathrm{g} \cdot \mathrm{ml}^{-1}\right)$ & $1.89 \pm 0.68$ & $10.32 \pm 4.3$ & $11.07 \pm 2.05$ \\
Data are means $\pm \mathrm{SD}$ & & & \\
\hline
\end{tabular}

(TBARS). The lipid soluble antioxidant $\alpha$-tocopherol (vitamin E) was measured by HPLC [20] and the total antioxidant capacity of serum was assayed using an enhanced chemiluminescent assay [21]. Analysis of red blood cell sorbitol, myoinositol, fructose and glucose levels was carried out by gas chromatography, as previously described [22, 23].

Analysis of collagen advanced glycation end products (AGEs). Samples of skin (1-inch square) were taken from the abdomen of each animal for analysis of collagen AGE levels. The collagen was prepared by shaving the tissue samples and extracted with 100 volumes (w/v) $0.5 \mathrm{mmol} / \mathrm{l} \mathrm{NaCl}$, chloroform/methanol $(2: 1)$ and $0.5 \mathrm{mmol} / \mathrm{l}$ acetic acid, respectively. Each extraction was carried out for $24 \mathrm{~h}$ at $4^{\circ} \mathrm{C}$ [24]. The samples were then washed thoroughly in deionised water and stored at $20^{\circ} \mathrm{C}$. Following hydrolysis of collagen $(\sim 6 \mathrm{mg}$ wet weight in $6 \mathrm{~mol} / \mathrm{l} \mathrm{HCl}$ for $24 \mathrm{~h}$ at $110^{\circ} \mathrm{C}$ ) the Maillard reaction products fructoselysine (FL), N-(carboxymethyl)lysine (CML) and $\mathrm{N}$-(carboxyethyl)lysine (CEL) were measured by selected ion monitoring gas chromatography-mass spectrometry as their $\mathrm{N}$-trifluoroacetyl methyl ester derivatives using heavy-labelled internal standards [24]. Pentosidine was measured by reversed phase HPLC using post-column fluorescence detection [25] and hydroxyproline by an established method [26].

Statistical analysis. Standard deviations were calculated and the data was analyzed using a one-way analysis of variance (ANOVA) and a Tukey-Kramer post-test for Multiple Comparisons. A $p$ value of 0.05 or less was considered to be statistically significant.

\section{Results}

Effect of Sulindac on metabolic parameters

\section{(i) Glycaemic control}

Mean fasting blood glucose levels of both the untreated diabetic animals $(16.9 \mathrm{mmol} / \mathrm{l} \pm 3.36)$ and the Sulindac-treated diabetics $(16.0 \mathrm{mmol} / \mathrm{l} \pm 3.86)$ were significantly elevated above those of the control animals (4.4 $\mathrm{mmol} / \mathrm{l} \pm 1.1),(p \leq 0.001)$; there was no difference in blood glucose levels between the two diabetic groups. Mean levels of glycated haemoglobin were also significantly increased in both groups of diabetic animals (untreated diabetic animals $6.90 \% \pm 1.55 \%$; Sulindac-treated diabetic animals $7.30 \% \pm 1.11 \%$ ) com- pared to control animals $(3.03 \% \pm 0.8 \%),(p \leq 0.05)$. There was no statistically significant difference in the level of glycated haemoglobin between the two diabetic groups. There were no significant differences in mean body weights at the end of the study between any of the three groups of animals (Table 1).

\section{(ii) Polyol pathway}

Red blood cell sorbitol levels were significantly increased in both diabetic groups compared to the controls $(p \leq 0.05)$, however, there was no difference in sorbitol levels between the untreated and the treated diabetic animals. No significant differences were found in red blood cell myoinositol levels between the three groups of animals. Both red blood cell glucose and fructose levels were significantly elevated in the two diabetic groups compared to the control animals $(p \leq 0.001)$ but no difference was found in glucose or fructose levels in the red cells between the treated and untreated diabetic animals (Table 1).

\section{(iii) Accumulation of AGEs}

After 4 years duration of diabetes the extent of glycation of skin collagen, measured as FL (Fig. 1A), was increased by approximately four-fold in the untreated diabetic animals consistent with the increase in blood sugar. Administration of Sulindac did not affect the glycation of skin collagen in the diabetic samples. The cross-link pentosidine was increased by two- to threefold in the diabetic animals $(p \leq 0.001)$, CML by twofold $(p \leq 0.001)$ and CEL by about $30 \%(p \leq 0.015)$ (Figs. 1B,C,D, respectively), however none of these AGEs were reduced by Sulindac treatment. There were strong correlations between levels of the various advanced Maillard products pentosidine, CML and CEL (CEL vs CML $p<0.00002$; CEL vs pentosidine $p<0.01$; CML vs pentosidine $p<0.00001)$. 


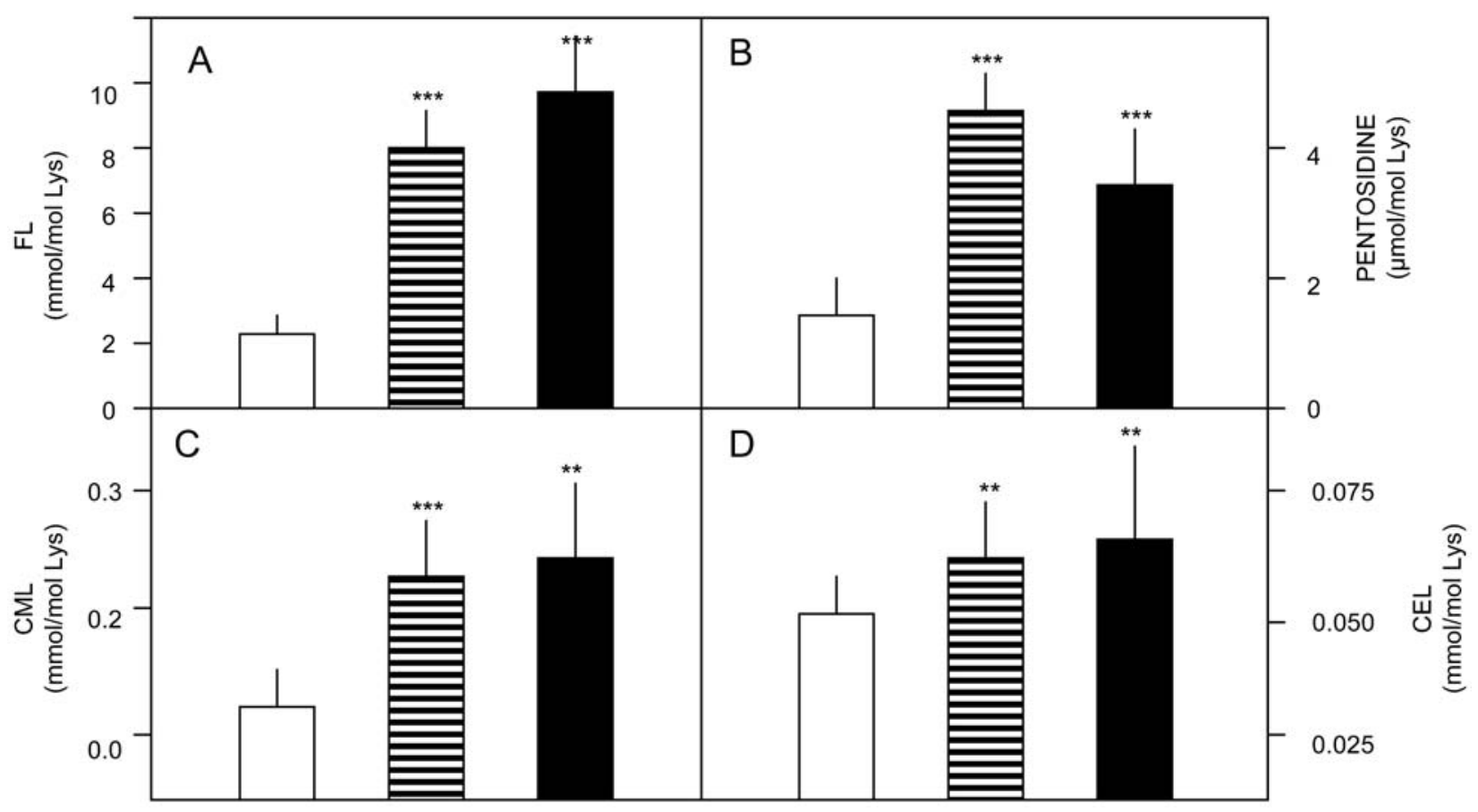

Fig. 1A-D. Estimation of AGEs in skin collagen from control, diabetic and Sulindactreated diabetic groups. The AGEs analysed were fructose lysine $(\mathrm{FL})(\mathbf{A})$, pentosidine $(\mathbf{B}), \mathrm{CML}(\mathbf{C})$ and CEL (D) and all show a highly significant increase when diabetic animals are compared to non-diabetic controls
$(* * * p<0.0001 ; * * p<0.01)$. In all AGEs measured, there was no difference between Sulindac-treated diabetics and diabetic controls. All AGEs are presented as $\mathrm{mmol} / \mathrm{mol}$ Lys. Results expressed as mean $\pm \mathrm{SD}$

Table 2. Levels of malondialdehyde (MDA), total antioxidant capacity, retinol and tocopherol $(\mu \mathrm{mol} / \mathrm{l})$

\begin{tabular}{llclr}
\hline & $\begin{array}{l}\text { Malondialdehyde } \\
(\text { MDA) } \mu \mathrm{mol} / \mathrm{L}\end{array}$ & $\begin{array}{l}\text { Total antioxidant } \\
\text { capacity } \mu \mathrm{mol} / \mathrm{L}\end{array}$ & Retinol $\mu \mathrm{mol} / \mathrm{L}$ & Tocopherol $\mu \mathrm{mol} / \mathrm{L}$ \\
\hline Untreated diabetics & $6.3 \pm 2.9$ & $104.2 \pm 2.7$ & $3.72 \pm 1.2$ & $14.1 \pm 3.9$ \\
Sulindac-treated diabetics & $6.2 \pm 3.2$ & $91.3 \pm 3.3$ & $3.97 \pm 1.5$ & $11.2 \pm 2.2$ \\
Controls & $5.0 \pm 4.1$ & $121.7 \pm 2.1$ & $2.77 \pm 1.0$ & $11.8 \pm 3.9$ \\
\hline
\end{tabular}

Results expressed as mean $\pm \mathrm{SD}$

\section{(iv) Oxidant status}

Levels of malondialdehyde (a marker of lipid peroxidation) were increased in both diabetic groups of animals compared to the controls $(\mathrm{p} \leq 0.05)$, but there was no difference in MDA levels between the untreated and Sulindac-treated diabetic animals. The total antioxidant capacity was significantly reduced in both the untreated and Sulindac-treated diabetic animals compared to the control animals $(\mathrm{p} \leq 0.05)$, but again there was no significant difference between the two diabetic groups. No significant differences were found in the level of alpha-tocopherol between any of the three groups of animals (Table 2).
Ultrastructural evaluation of retinal capillaries

Transmission electron microscopic examination of sections from all four trephines taken from each animal were analysed "blind" in the stereological study of BM thickness, but re-appraised following completion of that stage of the investigation and breaking of the code. At that time a major increase in the thickness of the retinal capillary BMs was obvious in the untreated diabetic dogs compared to the control animals (Figs. 2A,B). Also, a qualitative assessment of the BM of retinal capillaries in the Sulindac-treated diabetic animals (Fig. 2C) confirmed that they were visibly thinner than those of the untreated diabetic animals. However, no difference could be discerned in capillary basement thickness between controls and Sulindac-treated diabetic animals. A number of pericyte ghosts were observed in sections taken from a number of the untreated diabetic animals although no 

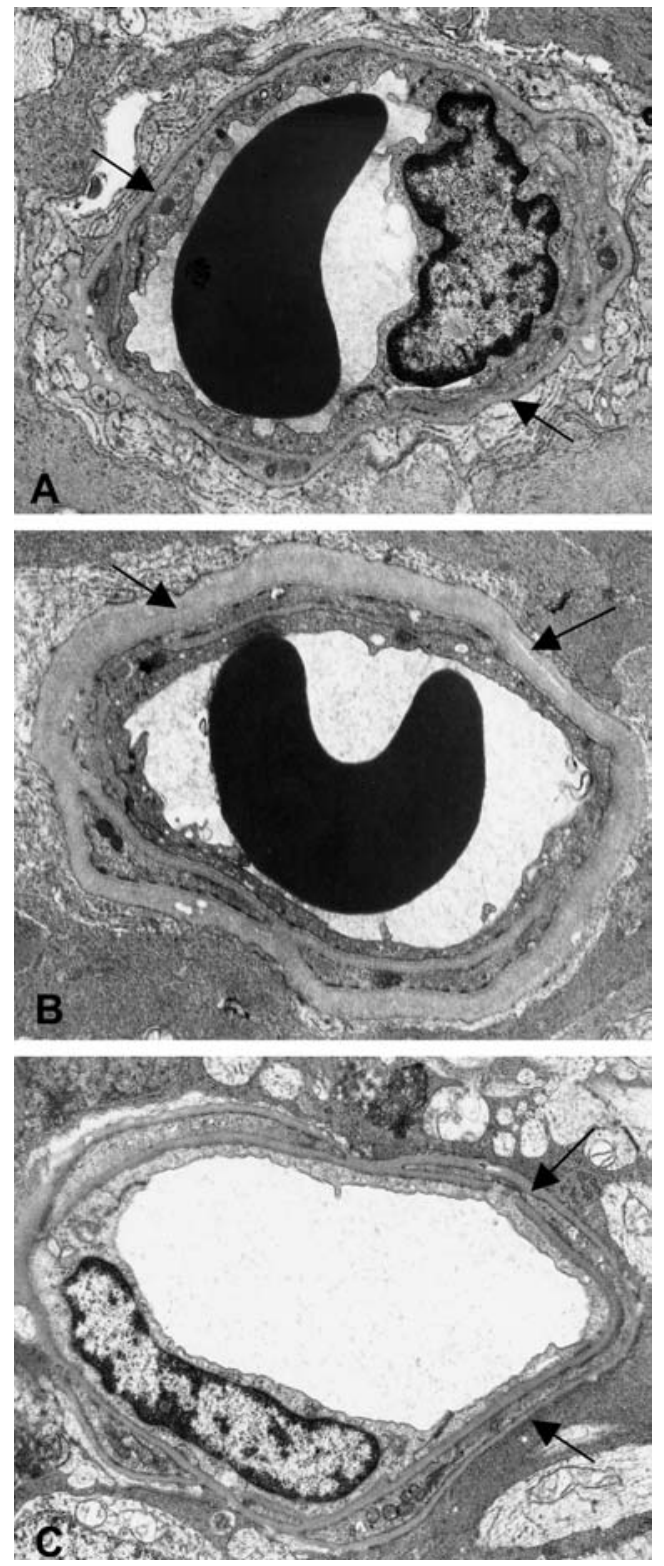

Fig. 2A-C. Transmission electron micrographs (TEMs) of retinal capillaries from diabetic and control dogs. (A) Retinal capillary from a control dog showing BM (arrows). (B) TEM of a retinal capillary from a 4-year untreated diabetic dog. The basement membrane appears considerably thickened (arrows) compared to that of the control. (C) Retinal capillary from a Sulindac-treated 4-year diabetic dog showing a basement membrane (arrows) which is obviously thinner than that of the untreated diabetic control. (Original magnification $\times 9000$ )

pericyte ghosts were found in any of the Sulindactreated diabetic animals or the controls and in any case were too few for meaningful comparison. No other qualitative ultrastructural changes were observed.

Stereological analysis showed that capillary $\mathrm{BM}$ volume/unit volume of neural retina was significantly increased in the untreated diabetic animals compared to the Sulindac-treated diabetics $(p \leq 0.0001)$ (Fig. 3).

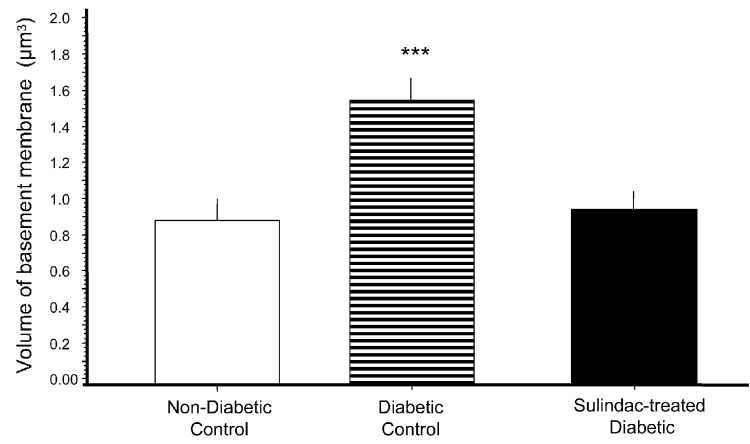

Fig. 3. Stereological evaluation of retinal capillary BM volume $\left(\mu \mathrm{m}^{3}\right)$. There is a significant increase in BM volume when nondiabetic control retinal capillaries are compared to diabetic control animals $(* * * p<0.001)$. Sulindac treatment appeared to prevent $\mathrm{BM}$ volume abnormalities in diabetic retinal capillaries and there was no significant difference between treated diabetic animals and non-diabetic control animals. Results expressed as means \pm SD

\section{Discussion}

This study has shown that treatment with the nonsteroidal inflammatory drug Sulindac significantly alters capillary BM thickening, a major hallmark and widely used surrogate end-point of diabetic microangiopathy. It has also shown that this benefit is not derived from inhibition of advanced glycation, reduction of sorbitol pathway activity or improvement in antioxidant status. The fact that Sulindac can reduce retinal capillary BM thickening was previously shown in another study [9] in diabetic cats; the authors attributed the treatment effect to inhibition of aldose reductase, although no data was presented to confirm such inhibition. Our study used the same dose of Sulindac as used in the aforementioned study and has shown that in spite of it's aldose reductase inhibitory activity in vitro $[11,12]$, in the diabetic dog this drug did not alter either sorbitol or fructose, the major products of the respective first and second stages of the polyol pathway. There has been considerable interest in the role of the polyol pathyway in the development of galactosaemia-induced retinopathy and diabetic retinopathy however, so far, evidence that inhibition of polyol accumulation prevents the development of retinopathy is conflicting $[9,27,28,29,30]$. The results of the current study show that inhibition of increased levels of sorbitol is not necessary for the prevention of capillary BM thickening in a long-term model of diabetic retinopathy.

Accumulation of AGEs in tissues in diabetes could have a role in the pathogenesis of diabetic retinopathy $[31,32]$. Therefore, this study included analysis of glycated haemoglobin, the AGE precursor fructose lysine (FL) and well characterised AGEs such as pentosidine, CML and CEL in skin collagen. In agreement with previous work in diabetic rats [33] and with earlier studies on the effect of caloric restriction in rats 
[34], pentosidine was found to be a more sensitive biomarker than CML of exposure of tissue proteins to Maillard reactions. In both rats and dogs, the three- to four-fold increase in pentosidine in diabetic animals closely paralleled the increase in glycaemia, while CML increased only two-fold and CEL to a lesser extent. Age-corrected decreases in pentosidine were also more pronounced than those of CML during lifetime caloric restriction of rats [34]. In contrast to pentosidine, which seems to be derived exclusively from carbohydrates, the chemical origin of CML and CEL is uncertain, that is, they could be derived from either carbohydrate autoxidation or lipid peroxidation reactions [35]. The increase in CEL is consistent with an increase in carbohydrate flux to triose phosphates via glycolysis and the reported increase in methylglyoxal concentration in blood of diabetic animals [36, 37]. Similar relative responses of pentosidine, CML and CEL in skin collagen have been observed in studies of STZ-diabetic rats and CML and CEL, but not pentosidine were decreased by the AGE inhibitor pyridoxamine $[31,33]$. Despite inhibiting of BM thickening in the current study, Sulindac had no effect on glycation of haemoglobin, FL or AGE-modification of skin collagen. Previous studies have shown that glycated collagen is more resistant to protease digestion suggesting that impaired turnover of BM components could contribute to the net accumulation in diabetes. However, inhibition of $\mathrm{BM}$ accumulation by a drug that doesn't inhibit glycation suggests that glycation-mediated resistance to proteolysis might only be a component factor in this pathology [6].

Another possible mechanism by which hyperglycaemia could induce diabetic complications is through the generation of oxidative stress [38, 39] and treatment with antioxidants has been shown to have beneficial effects on the development of diabetic retinopathy in rats [40]. Our study also measured levels of malondialdehyde (MDA), total antioxidant capacity and the levels of the antioxidant alpha-tocopherol. Results showed an increase in MDA (a marker of lipid peroxidation) and a reduction in the antioxidant status in the diabetic animals compared to the controls; changes which are known to occur in diabetes [40, 41]. However, Sulindac treatment did not prevent these changes indicating that according to these parameters, Sulindac does not act as an inhibitor of oxidative stress in diabetes.

In this study vascular BM accumulation was easily assessed using an efficient modern stereological method that doesn't necessitate laborious measurement of the limited number of capillary profiles that present as perfect transverse sections. While the advantages of this method are obvious, it could be argued that the parameter of BM volume could have been altered if excessive capillary fallout had occurred in the diabetic retinas. However, if such a change had occurred in the present situation it would have tended to reduce the volume of $\mathrm{BM}$ in the diabetic retinas making the observed result even more significant.

The present study demonstrates clear ultrastructural abnormalities in retinal capillary BM during the development of retinopathy in the diabetic dog and shows that this pathology can be prevented by treatment with the NSAID Sulindac. Other NSAIDs such as aspirin have been shown to prevent some of the early changes in the retinal capillaries during diabetes $[14,15]$. In another study its treatment benefit was clearly shown to be derived from its classic anti-inflammatory role as a NSAID [14] although this is generally less effective than drugs such as aminoguanidine [15]. In summary, it is clear that Sulindac is effective in the prevention of BM thickening during diabetic retinopathy in dogs, however the precise mode of action of this drug requires more investigation.

Acknowledgements. The authors would like to acknowledge the technical expertise of Mr S. Lloyd and Mr G. Creighton in this work. We would like to acknowledge Dr D. Mirrlees (Astra Zeneca Pharmaceuticals, Macclesfield, England, UK) for analysing sorbitol accumulation. We would also thank The Wellcome Trust and The Research and Development Office (NI) for their financial support.

\section{References}

1. DCCT Group (1993) The effect of intensive treatment of diabetes on the development and progression of long-term complications in insulin-dependent diabetes mellitus. New Engl J Med 329:977-986

2. Spranger J, Pfeiffer AF (2001) New concepts in pathogenesis and treatment of diabetic retinopathy. Exp Clin Endocrinol Diabetes 109:S438-S450

3. Bobbink IW, Boer HC de, Tekelenburg WL, Banga JD, Groot PG de (1997) Effect of extracellular matrix glycation on endothelial cell adhesion and spreading: involvement of vitronectin. Diabetes 46:87-93

4. Kalfa TA, Gerritsen ME, Carlson EC, Binstock AJ, Tsilibary EC (1995) Altered proliferation of retinal microvascular cells on glycated matrix. Invest Ophthalmol Vis Sci 36:2358-2367

5. Anderson HR, Stitt AW, Gardiner TA, Archer DB (1995) Diabetic retinopathy: morphometric analysis of basement membrane thickening of capillaries in different retinal layers within arterial and venous environments. $\mathrm{Br} \mathbf{J}$ Ophthalmol 79:1120-1123

6. Stitt AW, Anderson HR, Gardiner TA, Archer DB (1994) Diabetic retinopathy: quantitative variation in capillary basement membrane thickening in arterial or venous environments. Br J Ophthalmol 78:133-137

7. Engerman RL, Kern TS, Garment MB (1993) Capillary basement membrane in retina, kidney, and muscle of diabetic dogs and galactosemic dogs and its response to 5 years aldose reductase inhibition. J Diabetes Complications 7:241-245

8. Robison WG Jr, Nagata M, Kinoshita JH (1988) Aldose reductase and retinal capillary basement membrane thickening. Exp Eye Res 46:343-348

9. Mansour SZ, Hatchell DL, Chandler D, Saloupis P, Hatchell MC (1990) Reduction of basement membrane 
thickening in diabetic cat retina by sulindac. Invest Ophthalmol Vis Sci 31:457-463

10. Tugwell P, Ludwin D, Gent M et al. (1997) Interaction between cyclosporin A and nonsteroidal antiinflammatory drugs. J Rheumatol 24:1122-1125

11. Cruz-Correa M, Hylind LM, Romans KE, Booker SV, Giardiello FM (2002) Long-term treatment with sulindac in familial adenomatous polyposis: a prospective cohort study. Gastroenterology 122:641-645

12. Jacobson M, Sharma YR, Cotlier E, Hollander JD (1983) Diabetic complications in lens and nerve and their prevention by sulindac or sorbinil: two novel aldose reductase inhibitors. Invest Ophthalmol Vis Sci 24:1426-1429

13. Crabbe MJ, Freeman G, Halder AB, Bron AJ (1985) The inhibition of bovine lens aldose reductase by Clinoril, its absorption into the human red cell and its effect on human red cell aldose reductase activity. Ophthalmic Res 17:85-89

14. Joussen AM, Poulaki V, Mitsiades N, Kirchhof B, Koizumi K, Dohmen S, Adamis AP (2002) Nonsteroidal anti-inflammatory drugs prevent early diabetic retinopathy via TNF-alpha suppression. FASEB J 16:438-440

15. Kern TS, Engerman RL (2001) Pharmacological inhibition of diabetic retinopathy: aminoguanidine and aspirin. Diabetes 50:1636-1642

16. Anderson HR, Stitt AW, Gardiner TA, Lloyd SJ, Archer DB (1993) Induction of alloxan/streptozotocin diabetes in dogs: a revised experimental technique. Lab Anim 27:281-285

17. Anderson HR, Stitt AW, Gardiner TA, Archer DB (1994) Estimation of the surface area and volume of the retinal capillary basement membrane using the stereologic method of vertical sections. Anal Quant Cytol Histol 16:253-260

18. Baddeley AJ, Gundersen HJ, Cruz-Orive LM (1986) Estimation of surface area from vertical sections. J Microsc 142:259-276

19. Young IS, Trimble ER (1991) Measurement of malondialdehyde in plasma by high performance liquid chromatography with fluorimetric detection. Ann Clin Biochem 28:504-508

20. Catignani GL, Bieri JG (1983) Simultaneous determination of retinol and alpha-tocopherol in serum or plasma by liquid chromatography. Clin Chem 29:708-712

21. Chapple IL, Mason GI, Garner I, Matthews JB, Thorpe GH, Maxwell SR, Whitehead TP (1997) Enhanced chemiluminescent assay for measuring the total antioxidant capacity of serum, saliva and crevicular fluid. Ann Clin Biochem 34:412-421

22. Booth BP, Bennett BM, Brien JF, Elliott DA, Marks GS, McCans JL, Nakatsu K (1990) Assay of glyceryl trinitrate, isosorbide dinitrate, and their metabolites in plasma by large-bore capillary column gas-liquid chromatography. Biopharm Drug Dispos 11:663-677

23. Gremeau I, Sautou V, Pinon V, Rivault F, Chopineau J (1995) Solid-phase extraction of isosorbide dinitrate and two of its metabolites from plasma for gas chromatographic analysis. J Chromatogr B Biomed Appl 665:399-403

24. Dyer DG, Dunn JA, Thorpe SR, Bailie KE, Lyons TJ, McCance DR, Baynes JW (1993) Accumulation of Maillard reaction products in skin collagen in diabetes and aging. J Clin Invest 91:2463-2469

25. Dunn JA, McCance DR, Thorpe SR, Lyons TJ, Baynes JW (1991) Age-dependent accumulation of N epsilon-(carboxy- methyl)lysine and N epsilon-(carboxymethyl)hydroxylysine in human skin collagen. Biochemistry 30:1205-1210

26. Stegemann H, Stalder K (1967) Determination of hydroxyproline. Clin Chim Acta 18:267-273

27. Robison WG, Jr., Kador PF, Akagi Y, Kinoshita JH, Gonzalez R, Dvornik D (1986) Prevention of basement membrane thickening in retinal capillaries by a novel inhibitor of aldose reductase, tolrestat. Diabetes 35:295-299

28. Kern TS, Engerman RL (1991) Retinal polyol and myoinositol in galactosemic dogs given an aldose-reductase inhibitor. Invest Ophthalmol Vis Sci 32:3175-3177

29. Engerman RL, Kern TS (1993) Aldose reductase inhibition fails to prevent retinopathy in diabetic and galactosemic dogs. Diabetes 42:820-825

30. Kador PF, Akagi Y, Takahashi Y, Ikebe H, Wyman M, Kinoshita JH (1990) Prevention of retinal vessel changes associated with diabetic retinopathy in galactose-fed dogs by aldose reductase inhibitors. Arch Ophthalmol 108:1301-1309

31. Stitt A, Gardiner TA, Alderson NL et al. (2002) The AGE inhibitor pyridoxamine inhibits development of retinopathy in experimental diabetes. Diabetes 51:2826-2832

32. Stitt AW, Jenkins AJ, Cooper ME (2002) Advanced glycation end products and diabetic complications. Expert Opin Investig Drugs 11:1205-1223

33. Degenhardt TP, Fu MX, Voss E et al. (1999) Aminoguanidine inhibits albuminuria, but not the formation of advanced glycation end-products in skin collagen of diabetic rats. Diabetes Res Clin Pract 43:81-89

34. Cefalu WT, Bell-Farrow AD, Wang ZQ, Sonntag WE, Fu MX, Baynes JW, Thorpe SR (1995) Caloric restriction decreases age-dependent accumulation of the glycoxidation products, $\mathrm{N}$ epsilon-(carboxymethyl)lysine and pentosidine, in rat skin collagen. J Gerontol A Biol Sci Med Sci 50:B337-B341

35. Fu MX, Requena JR, Jenkins AJ, Lyons TJ, Baynes JW, Thorpe SR (1996) The advanced glycation end product, Nepsilon-(carboxymethyl)lysine, is a product of both lipid peroxidation and glycoxidation reactions. J Biol Chem 271:9982-9986

36. Ahmed MU, Brinkmann Frye E, Degenhardt TP, Thorpe SR, Baynes JW (1997) N-epsilon-(carboxyethyl)lysine, a product of the chemical modification of proteins by methylglyoxal, increases with age in human lens proteins. Biochem J 324:565-570

37. McLellan AC, Phillips SA, Thornalley PJ (1992) The assay of methylglyoxal in biological systems by derivatization with 1,2-diamino-4,5-dimethoxybenzene. Anal Biochem 206:17-23

38. Nishikawa T, Edelstein D, Du XL et al. (2000) Normalizing mitochondrial superoxide production blocks three pathways of hyperglycaemic damage. Nature 404:787-790

39. Baynes JW, Thorpe SR (1999) Role of oxidative stress in diabetic complications: a new perspective on an old paradigm. Diabetes 48:1-9

40. Kowluru RA, Kern TS, Engerman RL, Armstrong D (1996) Abnormalities of retinal metabolism in diabetes or experimental galactosemia. III. Effects of antioxidants. Diabetes 45:1233-1237

41. Armstrong D, al-Awadi F (1991) Lipid peroxidation and retinopathy in streptozotocin-induced diabetes. Free Radic Biol Med 11:433-436 